\title{
Electronic Structure and Bonding of the Ground State of Alkaline-Earth-Metal Monoxides and Carbides
}

\author{
P. Fuentealba*, ${ }^{*}$ and A. Savin \\ Departamento de Física, Facultad de Ciencias, Universidad de Chile, Casilla 653, Santiago de Chile, Chile, \\ and Laboratoire de Chimie Théorique, CNRS et Université Pierre et Marie, Curie, Place Jussieu, \\ F-75252 Paris Cedex 05, France
}

Received: May 3, 2000; In Final Form: August 30, 2000

\begin{abstract}
The electronic structure of the ground state of monoxides $\mathrm{MO}$ and carbides $\mathrm{MC}_{2}$ with $\mathrm{M}$ an alkaline-earthmetal atom ( $\mathrm{Be}$ to $\mathrm{Ba}$ ) has been investigated. Bond energies, vibrational frequencies, dipole moments and equilibrium bond lengths have been calculated using a hybrid density functional method. To understand the bonding characteristics, the ELF (electron localization function) and the NBO (natural bond orbitals) have been used. It has been found that despite many similarities between the monoxides and the carbides there is a difference in the bond formation. The results suggest that in the monoxides, and not in the carbides, a change in the type of bonding occurrs in going from the beryllium compound to the barium compound. For the carbides, all of them present an ionic bonding with a most favorable bent structure.
\end{abstract}

\section{Introduction}

The gas phase alkaline-earth-metal monoxides are difficult species to be studied in the laboratory. They are highly reactive with tendency toward reduction, dissociation and polymerization. They are, however, important in the chemiluminescent reactions of the alkaline-earth-metal atoms with oxidants. ${ }^{1}$ It has been experimentally proven that the ground state of those molecules, previously suggested to be of ${ }^{3} \Pi$ or ${ }^{3} \Sigma^{+}$symmetry, are in fact of ${ }^{1} \Sigma^{+}$symmetry. This result has been theoretically confirmed in a number of studies. ${ }^{2,3}$ The solid-state species are much more stable and exhibit several interesting physical properties which are related to their electronic structure. The ionic character of the bonding seems to be important to understand their structure and properties. ${ }^{4}$

On the other hand, owing to the well-known similarity between the $\mathrm{M}-\mathrm{O}$ and $\mathrm{M}-\mathrm{C}_{2}$ bond, one can expect similar characteristics for the alkaline-earth-metal carbides. For instance, it has been recently shown ${ }^{5}$ that the trends of the electron affinities and vibrational frequencies for the $\mathrm{MC}_{2}$ species $(\mathrm{M}$ being a first row transition metal) correlate well with the corresponding properties of the monoxides. They are, however, much more difficult to study in the gas phase. They decompose onto the elements upon vaporization. The knowledge of their existence and stability may be of practical interest in connection with energy conversion processes. ${ }^{6}$ To our knowledge, only the $\mathrm{BaC}_{2}$ molecule has been identified in the gas phase. ${ }^{6}$ On the contrary, the solid-state species are well-known and they present a large number of phases. $^{7}$ Like the alkaline-earth-metal monoxides their electronic and structure properties depend on the ionicity character of the bonding. More recently, the study of the metallocarbohedrenes of the type $\mathrm{M}_{8} \mathrm{C}_{12}$ has also demostrated the importance of the carbon-metal bonding. ${ }^{8}$

The theoretical study of ionic molecules has indicated that some states are well described at the single configuration level, others require a more general reference wave function. For the mentioned oxides previous theoretical works ${ }^{3}$ have demostrated

\footnotetext{
$\dagger$ Universidad de Chile. E-mail: pfuentea@abello.dic.uchile.cl.

$\doteqdot$ CNRS et Université Pierre et Marie.
}

that the study of the whole potential curve or the study of excited states require the use of MCSCF calculations but the spectroscopic properties $\left(R_{\mathrm{e}}, D_{\mathrm{e}}, \omega_{\mathrm{e}}\right)$ of the ground state are well described at the one Slater determinant reference wave function provided the nondynamical correlation energy is taken into account. In this paper we will show that the hybrid density functional methods ${ }^{9}$ provide a reliable tool to study the ground state of the alkaline-earth-metal monoxides and carbides around the equilibrium position. Although the metal carbides have been recently the subject of numerous studies, $, 5,10,11$ to our knowledge, this is the first study of the alkaline-earth-metal carbides. We carried out a systematic study of the ground-state oxides MO and carbides $\mathrm{MC}_{2}, \mathrm{M}=\mathrm{Be}-\mathrm{Ba}$, in the gas phase. Bond energies, vibrational frequencies, dipole moments, and equilibrium bond lengths have been calculated. To understand the bonding characteristics, the ELF (electron localization function) ${ }^{12}$ and the NBO (natural bond orbital) ${ }^{13}$ analyses have been used.

The ELF originally proposed by Becke and Edgecombe ${ }^{12}$ has been defined as

$$
\operatorname{ELF}(\vec{r})=\left[1+\left(\frac{D}{D_{0}}\right)^{2}\right]^{-1}
$$

where $D$ is the difference between the positive definite local kinetic energy of a system of noninteracting fermions, $T_{\mathrm{s}}[\rho]$, having the same density as the real system, and the von Weizsaecker kinetic energy functional, $T_{\mathrm{w}}[\rho]$,

$$
D[\rho]=T_{s}[\rho]-T_{\mathrm{w}}[\rho], \quad T_{\mathrm{w}}[\rho]=\frac{1|\nabla \rho|^{2}}{8 \rho}
$$

and $D_{0}$ is the local kinetic energy of a homogeneous electron gas

$$
D_{0}=c_{\mathrm{F}} \rho^{5 / 3}, \quad c_{\mathrm{F}}=2.781
$$

The range of values of ELF is between 0 and 1. The important term $D[\rho]$ has the physical meaning of the excess local kinetic 
TABLE 1: Ionization Potentials, Hardness, and Polarizabilities of the Alkaline-Earth-Metal Atoms ${ }^{a}$

\begin{tabular}{lccc}
\hline & $\mathrm{IP}(\mathrm{eV})$ & $\eta(\mathrm{eV})$. & $\alpha(\mathrm{au})$ \\
\hline $\mathrm{Be}$ & $9.02(9.322)$ & 5.03 & 42.00 \\
$\mathrm{Mg}$ & $7.50(7.646)$ & 4.39 & $74.6(75.0)$ \\
$\mathrm{Ca}$ & $6.21(6.114)$ & 3.24 & $146.8(169.0)$ \\
$\mathrm{Sr}$ & $5.77(5.695)$ & 3.13 & $184.7(186.0)$ \\
$\mathrm{Ba}$ & $5.22(5.211)$ & 2.65 & $253.1(268.0)$
\end{tabular}

${ }^{a}$ Experimental values $^{34,35}$ in parentheses.

energy density due to Pauli repulsion. The function ELF should demarcate the special regions where there are a shared-electron interaction as in covalent and metallic bonding and an unsharedelectron interaction such as ionic bonding. The ELF has been extensively used to analyze a variety of bonding systems. ${ }^{14,15}$ Furthermore, a topological interpretation of the ELF has been developed. ${ }^{16}$ Analyzing its gradient field, it is possible to characterize the maxima and basins. They found three types of maxima which from a chemical point of view correspond to core, bonding and nonbonding. The volume enclosed by all the trajectories ending at a given maximum defines the basin, and the integration of the electron density over the basin gives the electron population associated with the corresponding maximum. They can be interpreted from a chemical point of view as the electron population associated with the core, bonding and nonbonding regions. Note that the whole bonding analysis using the ELF does not depend on the orbitals. It could be directly calculated from the density by calculating $T_{\mathrm{S}}$ or some approximation to it. ${ }^{17,18}$

\section{Computational Details}

Since some of the molecules contain heavy atoms like $\mathrm{Sr}$ and $\mathrm{Ba}$ the use of pseudopotentials is essential. It is already well-known that for those metals a clear-cut separation between the $\mathrm{n}-\mathrm{s}$ valence space and the $(n-1) \mathrm{d}$ and $-\mathrm{p}$ orbitals is difficult to achieve. Therefore, the quasirelativistic pseudopotentials with 10 valence electrons developed by Kaupp et al. ${ }^{19}$ have been used for $\mathrm{Ca}$ through $\mathrm{Ba}$ atoms. To keep all calculations at the same level of approximation, pseudopotentials were also used for the light atoms of Be and $\mathrm{Mg}$. For Be and $\mathrm{Mg}$ atoms the two-valence electron pseudopotentials developed by Fuentealba et al. ${ }^{20}$ have been used. The $6 \mathrm{~s} 6 \mathrm{p} 5 \mathrm{~d} 1 \mathrm{f} /[5 \mathrm{~s} 5 \mathrm{p} 4 \mathrm{~d} 1 \mathrm{f}]$ basis sets developed by the Stuttgart group ${ }^{19}$ have been employed. The carbon and oxygen atoms are treated at the allelectron level using the 6-311G** basis set as it is implemented in the GAUSSIAN98 program, ${ }^{21-23}$ which has been used for all the calculations. The hybrid density functionals B3LYP, ${ }^{9}$ have been used. Since the interpretation of the ELF is sometimes obscured by the use of pseudopotentials, ${ }^{17}$ the calculations of ELF have been done at the all-electron level with the optimized geometry. It is also known that the ELF is not so sensitive to the basis set. Therefore, the $6-311 \mathrm{G}^{* *}$ basis set has been used for the calculations of ELF. The hardness has been calculated using the finite difference approximation as the energy difference between the HOMO and LUMO orbital energies.

\section{Results and Discussion}

For the purpose of calibrating the quality of the method and basis set used, atomic results are shown in Table 1. Ionization potentials, hardness and electric dipole polarizabilities are displayed. In general, the calculated values are in reasonable agreement with experimental values with few exceptions. For $\mathrm{Be}$, the calculated ionization potential is approximately $7 \mathrm{kcal} /$ mol too low. Comparing with the values presented in ref 20
TABLE 2: Atomization Energies (kcal/mol), Bond Lengths $(\AA)$, Vibrational Frequencies $\left(\mathrm{cm}^{-1}\right)$, Dipole Moments $(\boldsymbol{D})$, and Hardnesses $(\mathrm{eV})$ for the Alkaline-Earth-Metal Monoxides $^{a}$

\begin{tabular}{lccccc}
\hline & $\mathrm{BeO}$ & $\mathrm{MgO}$ & $\mathrm{CaO}$ & $\mathrm{SrO}$ & $\mathrm{BaO}$ \\
\hline$\Delta E_{\mathrm{at}}$ & 105.1 & 51.96 & 97.31 & 94.27 & 119.5 \\
& $(106.1)$ & $(59.0 \pm 5)^{b}$ & $(89.9)$ & $(99.2)$ & $(133.7)$ \\
$R_{\mathrm{e}}$ & 1.319 & 1.751 & 1.820 & 1.933 & 2.002 \\
& $(1.33)$ & $(1.75)$ & $(1.82)$ & $(1.92)$ & $(1.94)$ \\
$v_{\mathrm{e}}$ & 1512.0 & 789.0 & 769.0 & 667.0 & 648.0 \\
& $(1487.3)$ & $785.0)$ & $(732.1)$ & $(653.5)$ & $(669.8)$ \\
$\eta$ & 3.02 & 2.04 & 2.56 & 2.45 & 2.97
\end{tabular}

${ }^{a}$ In parentheses, experimental $\mathrm{D}_{o}$ and $\mathrm{R}_{e}$ values from ref 24 and vibrational frequencies from ref $25 .{ }^{b}$ From ref 26.

TABLE 3: Atomization Energies (kcal/mol), Bond Energies (kcal/mol), Bond Lengths (A), Angles (deg), Dipole Moments $(D)$, and Hardnesses $(\mathrm{eV})$ for the Alkaline-Earth-Metal Monoxides $^{a}$

\begin{tabular}{lccccc}
\hline & $\mathrm{BeC}_{2}$ & $\mathrm{MgC}_{2}$ & $\mathrm{CaC}_{2}$ & $\mathrm{SrC}_{2}$ & $\mathrm{BaC}_{2}$ \\
\hline$\Delta E_{\text {at }}$ & 254.3 & 221.1 & 254.8 & 253.1 & 267.4 \\
$\Delta E_{\mathrm{b}}$ & 137.4 & 104.2 & 137.9 & 136.1 & 150.5 \\
$R(\mathrm{MC})$ & 1.600 & 2.013 & 2.203 & 2.346 & 2.480 \\
$R(\mathrm{CC})$ & 1.266 & 1.267 & 1.266 & 1.265 & 1.265 \\
$\angle(\mathrm{CMC})$ & 46.6 & 36.7 & 33.4 & 31.3 & 29.6 \\
$\mu$ & 4.79 & 8.75 & 10.7 & 11.5 & 11.9 \\
$\eta$ & 3.47 & 2.10 & 2.58 & 2.50 & 2.72 \\
\multicolumn{5}{c}{${ }^{a} \Delta E_{\mathrm{at}}=E(\mathrm{M})=2 E(\mathrm{C})-E\left(\mathrm{MC}_{2}\right) . \Delta E_{\mathrm{b}}=E(\mathrm{M})+E\left(\mathrm{C}_{2}\right)-E\left(\mathrm{MC}_{2}\right)}$.
\end{tabular}

$\mathrm{M}$ : alkaline-earth-metal atom. $\mathrm{C}$ : carbon atom.

using the same pseudopotential, it is clear that the error is due to the known failure of the currently used density functionals to properly account for the nondynamical correlation. The calculated hardnesses show the expected trend in going down the column of the periodical table.

In Table 2 some calculated properties of the ground state of the alkaline-earth-metal monoxides are presented: atomization energies, bond lengths, vibrational frequencies, dipole moments and hardnesses. The experimental values are shown in parentheses. The calculated atomization energies do not contain the zero point energy which is, however, only of significance for $\mathrm{BeO}(2.16 \mathrm{kcal} / \mathrm{mol})$. The only major discrepancy with the experimental values is a difference of $14.2 \mathrm{kcal} / \mathrm{mol}$ for $\mathrm{BaO}$, where there are other relativistic effects, like spin-orbit coupling, which are not included in the pseudopotential. The bond lengths are within $0.01 \AA$ of the experimental values, with the exception again of $\mathrm{BaO}$, and the vibrational frequencies are systematically above the experimental values by $10-20 \mathrm{~cm}^{-1}$. The results confirm the capability of our calculations to do semiquantitative predictions. The important point to be stressed here is that none of the displayed properties follows a periodic, continuous trend, which suggests that a change in the type of bonding ocurrs in going from beryllium oxide to the barium oxide.

In Table 3, the atomization energies, the $\mathrm{M}-\mathrm{C}_{2}(\mathrm{M}: \mathrm{Be}-$ Ba) bonding energies, bond lengths, angles, dipole moments and hardnesses are presented. For all the alkaline-earth-metal carbides, to our knowledges, only the $\mathrm{BaC}_{2}$ molecule has been experimentally detected. Gingerich et al. ${ }^{6}$ using a Knudsen effusion mass spectrometer determined the atomization energy, $282.5 \pm 2.9 \mathrm{kcal} / \mathrm{mol}$, and the binding energy, $139.2 \pm 3.5 \mathrm{kcal} /$ mol, which after adding the zero point energy of around 3.6 $\mathrm{kcal} / \mathrm{mol}$ are in reasonable agreement with the calculated values. The deviations can be traced to the assumptions for the interpretation of the measurements. They assumed a linear geometry with a $\mathrm{Ba}-\mathrm{C}$ bond length of $1.97 \AA$ whereas the calculations predict a nonlinear geometry with a much longer 
TABLE 4: Vibrational Frequencies of the Alkaline-Earth-Metal Carbides $\left(\mathrm{cm}^{-1}\right)^{a}$

\begin{tabular}{lrrrrr}
\hline & $\mathrm{BeC}_{2}$ & $\mathrm{MgC}_{2}$ & $\mathrm{CaC}_{2}$ & $\mathrm{SrC}_{2}$ & $\mathrm{BaC}_{2}$ \\
\hline$v_{1}$ & 644.0 & 414.0 & 387.0 & 363.0 & 314.0 \\
$v_{2}$ & 1078.0 & 603.0 & 554.0 & 467.0 & 433.0 \\
$v_{3}$ & 1809.0 & 1771.0 & 1823.0 & 1822.0 & 1830.0 \\
$a$ & $\nu_{1}:$ bend. $v_{2}$ and $v_{3}:$ symmetric and asymmetric stretches.
\end{tabular}

$\mathrm{Ba}-\mathrm{C}$ bond length, $2.48 \AA$. For all the molecules the stability of the linear and bending geometries in triplet and singlet states have been tested. In all cases, the ground-state happens to be the triangle $C_{2 v}$ singlet state. The linear singlet structure has been found to be a minimum only for $\mathrm{BeC}_{2}$ and $\mathrm{MgC}_{2}$ lying 23.5 and $7.0 \mathrm{kcal}$ above the ground state, respectively. For the other carbides only a saddle point has been found. No linear triplet structure has been found, and the angular triplet lies 31.5 and $5.0 \mathrm{kcal}$ above the ground state for $\mathrm{BeC}_{2}$ and $\mathrm{MgC}_{2}$, respectively. To determine the right energy ordering between the linear singlet and the bent triplet, more ellaborate calculations are necessary. The carbides present some similarities with the monoxides. However, for the carbides the calculated spectroscopic properties follow a periodic, continuous trend (excepting the hardness for $\mathrm{BeC}_{2}$ ). The same behavior is exhibited in Table 4 where the vibrational frequencies are displayed. The present results are in agreement with the hypothesis that the electronic structure of the carbides, $\mathrm{MC}_{2}$, should be similar to the ionic structure of the monoxides, $\mathrm{MO}$, with the $\mathrm{C}_{2}{ }^{2-}$ moiety acting like the $\mathrm{O}^{2-}$ anion. However, the results suggest that in the monoxides, and not in the carbides, a change in the type of bonding occurs in going from the beryllium compound to the barium compounds.

The electron localization function, ELF, ${ }^{12}$ and natural bond analysis ${ }^{27}$ has been used to investigate the bonding characteristics of the compounds studied in this paper. Let us first analyze the results obtained by ELF (see Figures 1 and 2), produced with the TopMod package, ${ }^{28}$ Mathematica ${ }^{29}$ (graphics of Figure 1) and Vis5d (graphics of Figure 2). The dominant feature is the predominantly ionic character of the bonding, as the oxygen atom, and the $\mathrm{C}_{2}$ group are surrounded by a region of high ELF values, having a nearly spherical shape around $\mathrm{O}$, like a noble gas atom (cf. ref 14), or similar to $\mathrm{N}_{2}$ (isoelectronic with $\mathrm{C}_{2}{ }^{2-}$, cf. ref 14). The integration of the electron density in the corresponding basins support this visual impression, as it roughly yields the number of valence electrons in the molecule. A more careful look reveals, however, that there is a region of high ELF values between the $\mathrm{Be}$ and $\mathrm{O}$ cores, an indication for a covalent character of the $\mathrm{Be}-\mathrm{O}$ bond. The ELF maximum is present, but only weakly emphasized. This characteristic may be an explanation for the special position of $\mathrm{BeO}$ in the series. The ELF pictures show a special, unusual feature for $\mathrm{MgO}$ and $\mathrm{CaO}$ : a maximum behind the metal ion. While such features are common for lone pairs (cf. $\mathrm{SnO}^{14}$ ), it is unexpected in the present case. An explanation may be that part of the charge remains on the metal ion (the basin populations are quite small: 0.3 for $\mathrm{Mg}$ and 0.2 for $\mathrm{Ca}$ ), but it is not used for bonding. Of course, we cannot exclude the possibility that this maximum is an artifact of the calculation in the low-density region. The Laplacian of the density ${ }^{30}$ or the gradient of the logarithm of the density ${ }^{31}$ seem not to show this feature. Notice, however, that the change in basin population is not contradicted by the NBO analysis presented below.

The results for the alkaline-earth-metal monoxides are shown in Table 5. For all the molecules with the exception of $\mathrm{MgO}$, there are clear charge retrodonations from the oxygen anion to a $\mathrm{p}$ orbital in the case of $\mathrm{BeO}$, or a d orbital in the other
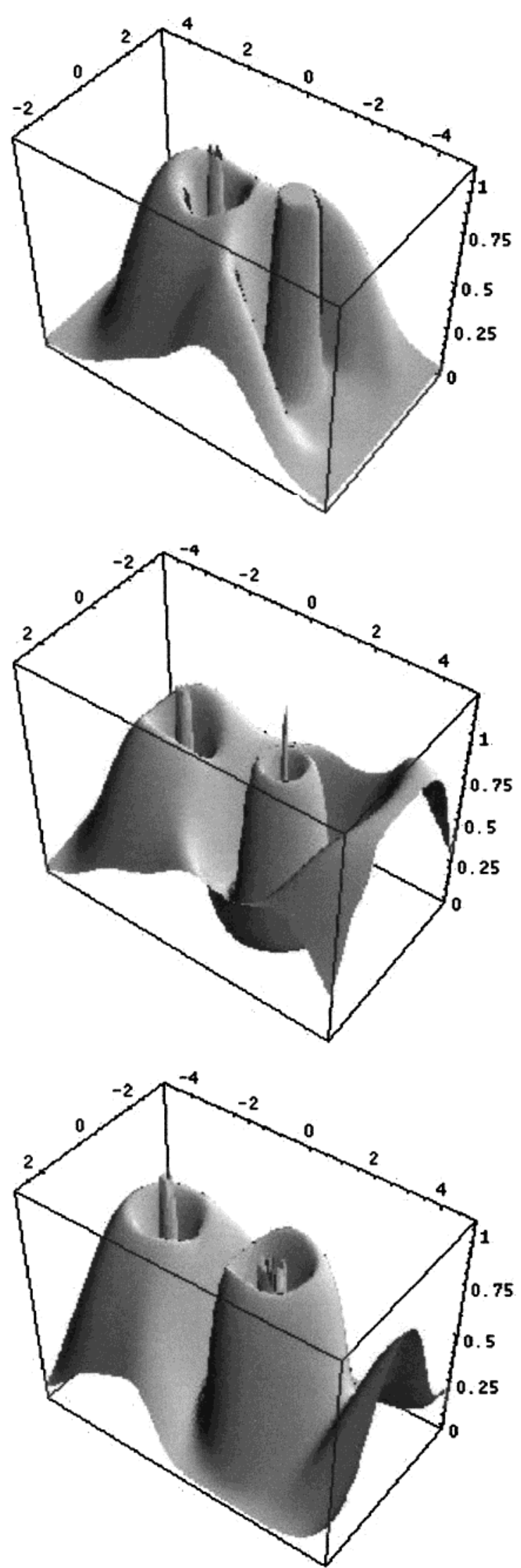

Figure 1. ELF in the oxides of $\mathrm{Be}, \mathrm{Mg}$, and $\mathrm{Ca}$, from top to bottom. The ELF values are represented in the planes containing the nuclei, the oxygen atom being left.

molecules. In $\mathrm{MgO}$ the $\mathrm{p}$ orbital population is negligible. We explain it by the fact that the 3p orbital of $\mathrm{Mg}$ is not as easily used as the $2 \mathrm{p}$ orbital in Be and $3 \mathrm{~d}$ orbital in Ca. For Be the $2 \mathrm{p}$ 

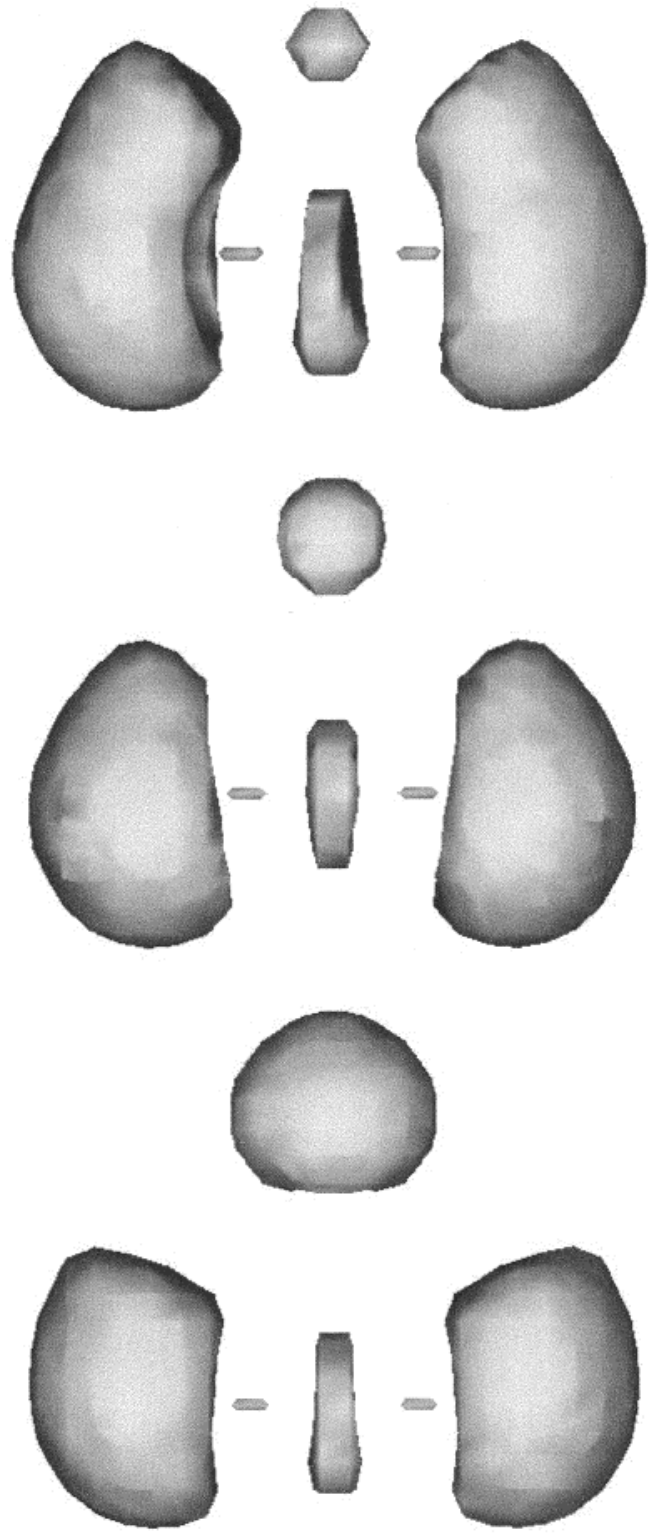

Figure 2. ELF in the carbides of $\mathrm{Be}, \mathrm{Mg}$, and $\mathrm{Ca}$, from top to bottom. The ELF isosurface of 0.8 is shown. The alkaline-earth-metal atom is above the $\mathrm{C}_{2}$ group.

TABLE 5: Natural Bond Orbital Population Analysis of the Alkaline-Earth-Metal Oxides

\begin{tabular}{llc}
\hline & \multicolumn{1}{c}{ natural electron configuration } & natural charge \\
\hline $\mathrm{Be}$ & $2 \mathrm{~s}(0.09) 2 \mathrm{p}(0.27)$ & +1.607 \\
$\mathrm{O}$ & $2 \mathrm{~s}(1.97) 2 \mathrm{p}(5.63)$ & -1.607 \\
$\mathrm{Mg}$ & $3 \mathrm{~s}(0.50) 3 \mathrm{p}(0.08)$ & +1.40 \\
$\mathrm{O}$ & $2 \mathrm{~s}(1.99) 2 \mathrm{p}(5.41)$ & -1.40 \\
$\mathrm{Ca}$ & $4 \mathrm{~s}(0.05) 3 \mathrm{~d}(0.43) 4 \mathrm{p}(0.06)$ & +1.48 \\
$\mathrm{O}$ & $2 \mathrm{~s}(1.99) 2 \mathrm{p}(5.49)$ & -1.48 \\
$\mathrm{Sr}$ & $5 \mathrm{~s}(0.03) 4 \mathrm{~d}(0.41) 5 \mathrm{p}(0.07)$ & +1.52 \\
$\mathrm{O}$ & $2 \mathrm{~s}(1.99) 2 \mathrm{p}(5.52)$ & -1.52 \\
$\mathrm{Ba}$ & $6 \mathrm{~s}(0.01) 5 \mathrm{~d}(0.45) 6 \mathrm{p}(0.07) 4 \mathrm{f}(0.01)$ & +1.52 \\
$\mathrm{O}$ & $2 \mathrm{~s}(1.99) 2 \mathrm{p}(5.50)$ & -1.52
\end{tabular}

orbital is in the same spatial region as the $2 \mathrm{~s}$ and for $\mathrm{Ca}$ the $3 \mathrm{~d}$ is in the same spatial region as the 4 s orbital, while the $3 \mathrm{~s}$ and $3 \mathrm{p}$ orbitals of $\mathrm{Mg}$ are in different spatial domains. ${ }^{32,33}$

In Figure 2, for the molecules $\mathrm{BeC}_{2}, \mathrm{MgC}_{2}$ and $\mathrm{CaC}_{2}$ the $\mathrm{ELF}=0.8$ isosurfaces are displayed. On the top of each plot one can see the alkaline-earth-metal ion which is increasing in size going down from $\mathrm{Be}$ to $\mathrm{Ca}$. The carbon cores are the two small points and between them one can identify the basin
TABLE 6: Natural Bond Orbital Population Analysis of the Alkaline-Earth-Metal Carbides

\begin{tabular}{lcc}
\hline & natural electron configuration & natural charge \\
\hline $\mathrm{Be}$ & $2 \mathrm{~s}(0.54) 2 \mathrm{p}(0.16)$ & +1.29 \\
$\mathrm{C}$ & $2 \mathrm{~s}(1.45) 2 \mathrm{p}(3.15)$ & -0.65 \\
$\mathrm{Mg}$ & $3 \mathrm{~s}(0.66) 3 \mathrm{p}(0.03)$ & +1.28 \\
$\mathrm{C}$ & $2 \mathrm{~s}(1.45) 2 \mathrm{p}(3.15)$ & -0.64 \\
$\mathrm{Ca}$ & $4 \mathrm{~s}(0.34) 3 \mathrm{~d}(0.25) 4 \mathrm{p}(0.01)$ & +1.41 \\
$\mathrm{C}$ & $2 \mathrm{~s}(1.47) 2 \mathrm{p}(3.19)$ & -0.71 \\
$\mathrm{Sr}$ & $5 \mathrm{~s}(0.32) 4 \mathrm{~d}(0.22) 5 \mathrm{p}(0.02)$ & +1.45 \\
$\mathrm{C}$ & $2 \mathrm{~s}(1.47) 2 \mathrm{p}(3.21)$ & -0.73 \\
$\mathrm{Ba}$ & $6 \mathrm{~s}(0.21) 5 \mathrm{~d}(0.28) 6 \mathrm{p}(0.03)$ & +1.52 \\
$\mathrm{C}$ & $2 \mathrm{~s}(1.48) 2 \mathrm{p}(3.23)$ & -0.76
\end{tabular}

corresponding to the $\mathrm{CC}$ bond. Behind each of the carbon atoms one find a large basin. The population of the basins are similar in the three molecules. The basins representing the $\mathrm{CC}$ bond have a population of 3.5, 3.5, and 3.7 for $\mathrm{BeC}_{2}, \mathrm{MgC}_{2}$ and $\mathrm{CaC}_{2}$, respectively. On the other hand, the population of the basins behind the carbon atom have a population of 3.1, 3.0, and 2.9 for $\mathrm{BeC}_{2}, \mathrm{MgC}_{2}$ and $\mathrm{CaC}_{2}$, respectively. We did not notice three-center bonds, but rather a deformation ("polarization") of the lone pairs of $\mathrm{C}_{2}{ }^{2-}$ toward the metal ion so that the bonding picture emerging from the ELF analysis corresponds to a strongly ionic bonding between the metal ion and the $\mathrm{C}_{2}{ }^{2-}$ moeity, and each carbon atom contains one lone pair plus an electron. The most representative Lewis structure should be of the type $\mathrm{M}^{+2}[: \dot{\mathrm{C}}=\dot{\mathrm{C}}:]^{-2}$. In contrast to the monoxides, there is no indication of a different bonding going down the series of the alkaline-earth-metal carbides. This is also clear when comparing the natural bond orbital populations which are displayed in Table 6 for the carbides. Whereas in the monoxides it is clear that only $\mathrm{Mg}$ has a significant population of the $\mathrm{s}$ orbital, in the carbides all of them have an important population of the s orbitals.

Concluding, the electronic structure of the alkaline-earth-metal monoxides and carbides in the ground state has been characterized. Dissociation energies, geometries, vibrational frequencies, dipole moments and hardnesses have been calculated using a hybrid density functional scheme. The nature of the bonding has been studied using the ELF and NBO analysis. It has been found that despite many similarities between the monoxides and the carbides there is a difference in the bond formation. For the monoxides, $\mathrm{BeO}$ is the only one presenting some covalent bond character while the other oxides are clearly ionic. For the carbides, all of them present an ionic bonding with a most favorable bent structure.

Acknowledgment. Part of this work has been supported by FONDECYT (Fondo de Desarrollo Cientifico y Tecnologico), grants 1981231 and 7980081.

\section{References and Notes}

(1) Irvin, J. A.; Dagdigian, P. J. J. Chem. Phys. 1980, 66, 1013.

(2) Diffenderfer, R. N.; Yarkoni, D. R. J. Chem. Phys. 1982 77, 5573.

(3) Bauschlicher, C. W.; Lengsfield, B. H.; Silver, D. M.; Yarkoni, D. R. J. Chem. Phys. 1981, 74, 2379.

(4) Joshi, K. B.; Jain, R.; Pandya, R. K.; Ahuja, B. L.; Sharma, B. K. J. Chem. Phys. 1999, 111, 163.

(5) Li, X.; Wang, L. J. Chem. Phys. 1999, 1118389.

(6) Gingerich, K. A.; Choudary, V. V.; Krishnan, K. J. Chem. Phys. 1985, 83, 1237

(7) Ruiz, E.; Alemany, P. J. Phys. Chem. 1995, 99, 3114.

(8) Rohmer, M.; Benard, M.; Poblet, J. Chem. Rev. 2000, 100495.

(9) Becke, A. D. J. Chem. Phys. 1993, 98, 5648.

(10) Roszak, S.; Balasubramanian, K. J. Phys. Chem. A 1997, 101, 2666.

(11) Nash, B. K.; Rao B. K.; Jena, P. J. Chem. Phys. 1996, 105, 11020.

(12) Becke, A. D.; Edgecombe, K. E. J. Chem. Phys. 1990, 92, 5397. 

899.

(13) Reed, A. E.; Curtiss, L. A.; Weinhold, F. Chem. Rev. 1988, 88,

(14) Savin, A.; Becke, A. D.; Flad, J.; Nesper, R.; Preuss, H.; von Schnering, H. Angew. Chem., Int. Ed. Engl. 1991, 30, 409.

(15) Savin, A.; Nesper, R.; Wengert, S.; Fassler, T. Angew. Chem., Int. Ed. Engl. 1997, 36, 1808

(16) Silvi, B.; Savin, A. Nature 1994, 371, 683.

(17) Kohout, M.; Savin, A. J. Comput. Chem. 1997, 18, 1431.

(18) Fuentealba, P. Int. J. Quantum Chem. 1998, 69, 559.

(19) Kaupp, M.; Schleyer, P. v. R.; Stoll, H.; Preuss, H. J. Chem. Phys. 1991, 94, 1360

(20) Fuentealba, P.; Szentpaly, L. v.; Preuss, H.; Stoll, H. J. Phys. B $1985,18,1287$

(21) Frisch, M. J.; Trucks, G. W.; Schlegel, H. B.; Scuseria, G. E.; Robb, M. A.; Cheeseman, J. R.; Zakrzewski, V. G.; Montgomery, J. A., Jr.; Stratmann, R. E.; Burant, J. C.; Dapprich, S.; Millam, J. M.; Daniels, A D.; Kudin, K. N.; Strain, M. C.; Farkas, O.; Tomasi, J.; Barone, V.; Cossi, M.; Cammi, R.; Mennucci, B.; Pomelli, C.; Adamo, C.; Clifford, S. Ochterski, J.; Petersson, G. A.; Ayala, P. Y.; Cui, Q.; Morokuma, K.; Malick, D. K.; Rabuck, A. D.; Raghavachari, K.; Foresman, J. B.; Cioslowski, J.; Ortiz, J. V.; Stefanov, B. B.; Liu, G.; Liashenko, A.; Piskorz, P.; Komaromi, I.; Gomperts, R.; Martin, R. L.; Fox, D. J.; Keith, T.; Al-Laham, M. A.; Peng, C. Y.; Nanayakkara, A.; Gonzalez, C.; Challacombe, M.; Gill, P. M W.; Johnson, B.; Chen, W.; Wong, M. W.; Andres, J. L.; Gonzalez, C. Head-Gordon, M.; Replogle, E. S.; Pople, J. A. Gaussian 98, revision A.3 Gaussian, Inc.: Pittsburgh, PA, 1998.

(22) Curtiss, L. A.; Raghavachari, K.; Pople, J. A. J. Chem. Phys. 1993 $98,1293$.
(23) Shaefer, A.; Huber, C.; Ahlrichs, R. J. Chem. Phys. 1994, 100, 5829

(24) Boldyrev, A. I.; Simons, J. Periodic Table of Diatomic Molecules; John Wiley: New York, 1977.

(25) Huber, K.; Herzberg, G. Molecular Spectra and Molecular Structure; D. van Nostrand: New York 1979.

(26) Bellert, D.; Burns, K.; Wampler, R.; Breckenridge, W. Chem. Phys Chem. 2000, 322, 41. Operti L.; Tews ,E.; MacMahon, T.; Freiser, B. J. Am. Chem. Soc. 1989, 111, 9152.

(27) Glendening, E. D.; Reed, A. E.; Carpenter, J. E.; Weinhold F.; Reed, A. E.; Curtiss L. A.; Weinhold F. NBO Version 3.1. Chem. Rev. 1988, 88 899

(28) Nouri, S.; Krokidis, X.; Fuster, F.; Silvi, B. TopMod package; Université Pierre et Marie Curie, 1997; http://www.lct.jussieu.fr.

(29) Wolfram, S. The Mathematica Book; Wolfram Media: Cambridge, U.K., 1996.

(30) Bader, R. F. W. Atoms in Molecules: A Quantum Theory; Oxford University Press: Oxford, U.K., 1990.

(31) Kohout, M.; Savin, A.; Preuss, H. J. Chem. Phys. 1990, 95, 1928. Sperber, G. Int. J. Quantum Chem. 1971, 5, 189. Hunter, G. Int. J. Quantum Chem. 1986, 29, 197.

(32) Kutzelnigg, W. Angew. Chem. 1984, 96, 262.

(33) Berski, S.; Silvi, B.; Latajka, Z.; Leszczynski, J. J. Chem. Phys. 1999, 111, 2542.

(34) Moore, C. E. Atomic Energy Levels. NBS Circular 467; NBS: Washington, DC, 1949.

(35) Miller, T. M.; Bederson, B. Adv. At. Mol. Phys. 1977, 13, 1. 